\title{
Absence of left musculocutaneous nerve \& variant origin of left ulnar nerve-a case report
}

\begin{abstract}
The knowledge of variations in anatomy of the brachial plexus is of great importance to anatomists, radiologists, anaesthesiologists and surgeons. Here, we report the variation of the absence of the musculocutaneous nerve and the rare origin of the ulnar nerve in a male cadaver on the left side during routine educational dissection in the academic year (2008-2009) in the department of anatomy at Siddhartha medical college in Vijayawada.
\end{abstract}

Keywords: brachial plexus, musculocutaneous nerve, ulnar nerve
Volume 6 Issue I - 2019

\author{
Shakthi Kumaran R,' Chitra R² \\ 'Aarupadai Veedu Medical College, Puducherry, India \\ ${ }^{2}$ Siddhartha Medical College, Andhra Pradesh, India
}

Correspondence: Chitra R, Professor \& HOD in Anatomy, Siddhartha medical college, Vijayawada-520008, AP, India, Tel 0866-2576319,+91-944-0508509, Email vjwchitra@yahoo.co.in

Received: January 29, 2019 | Published: February 15, 2019

\section{Introduction}

The brachial plexus is constituted by the ventral rami of spinal cervical nerves including $\mathrm{C} 5-\mathrm{C} 8$ and the first thoracic spinal nerve. There are five stages in the brachial plexus-root, trunk, division, cord and branch stages. The branches of the lateral cord are the lateral pectoral nerve, the musculocutaneous nerve and the lateral root of median nerve. The branches of the medial cord are the medial pectoral nerve, the medial cutaneous nerves of arm and forearm, the median and the ulnar nerves. The branches of the posterior cord are the upper and lower subscapular nerves, the nerve to latissimus dorsi, the axillary and the radial nerves. ${ }^{1}$

\section{Case presentation}

During routine educational dissection in the academic year (20082009), in a male cadaver on the left side in the department of anatomy at Siddhartha medical college in Vijayawada, the lateral cord of brachial plexus after giving lateral pectoral nerve, divided in to two divisions. They were the lateral root of median nerve and another division which gave a branch to coracobrachialis along with the lateral cutaneous nerve of forearm. The musculocutaneous nerve was absent on the left side. The lateral root joined with the medial root and then the median nerve proper and the ulnar nerves were formed. The median nerve gave branches to biceps brachii and brachialis muscles (Figure 1). The branches of the cords of brachial plexus were normal on the right side.

\section{Discussion}

Absence of musculocutaneous nerve has been reported by many authors. Bergman et al. ${ }^{2}$ reported that musculocutaneous nerve arises from the lateral cord in $90 \%$ and in $2 \%$ of the cases it may arise from the median nerve or may be completely absent. Le Minor ${ }^{3}$ and Gümusburun ${ }^{4}$ classified five types of communications between median and musculocutaneous nerves. The 5th type is the complete absence of musculocutaneous nerve, where anterior arm muscles will be supplied by the median nerve. Our present case of absence of the muculocutaneous nerve is the 5th type in the above classifications. The branch to coracobrachialis arising from the lateral cord of brachial plexus has been reported by Tatar ${ }^{5}$. Sachdeva $\&$ Singla $^{6}$ reported a rare origin of ulnar nerve from median nerve as in the present case report.

\section{Conclusion}

Anatomical abnormalities of the brachial plexus may affect the procedures of the various brachial plexus blockades that have been extensively utilized as a component of anesthesia for upper extremity surgeries. ${ }^{7}$ A better understanding of the brachial plexus variations may lead to a facilitated nerve blockage.

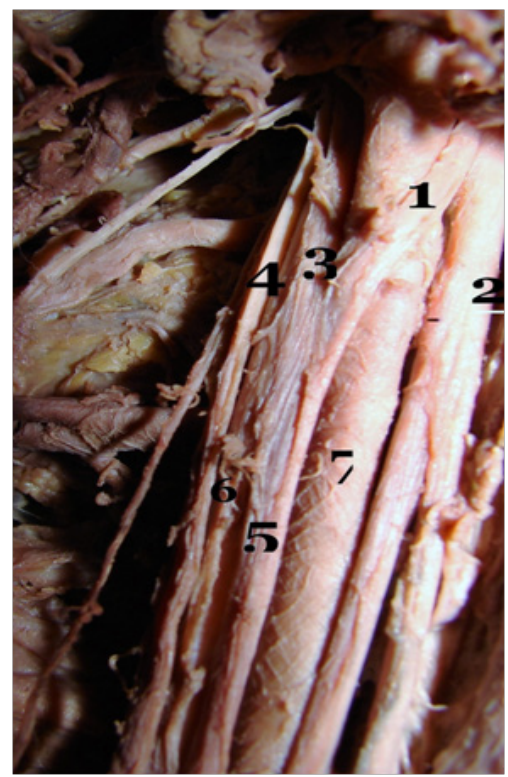

Figure I Absence of left musculocutaneous nerve and rare origin of ulnar nerve

I, Lateral root of median nerve; 2, Division which gives a branch to coracobrachialis and lateral cutaneous nerve of forearm; 3 , Medial root of median nerve; 4, Medial cutaneous nerve of forearm; 5, Median nerve; 6 , Ulnar nerve; 7 , Brachial artery

\section{Acknowledgments}

None.

\section{Conflicts of interest}

The authors declare there is no conflicts of interest.

\section{References}

1. Hollinshead W. Anatomy for Surgeons. New York: Hoeber-Harper; 1958.

2. Bergman RA, Thompson SA, Afifi AK, et al. Compendium of human anatomic variation: catalogue, atlas, and world literature. Baltimore, Munich: Urban and Schwarzenberg; 1988.

3. Le Minor JM. A rare variation of the median and musculocutaneous nerves in man. Arch Anat Histol Embryol. 1990;73:33-34. 
4. Gümüsburun E, Adigüzel E. A variation of the brachial plexus characterized by the absence of the musculocutaneous nerve- a case report. Surg Radiol Anat. 2000;22(1):63-65.

5. Tatar I, Brohi R, Sen F, et al. Innervation of the coracobrachialis muscle by a branch from the lateral root of the median nerve. Folia Morphol. 2004:63(4):503-506.
6. Sachdeva K, Singla RK. An unusual origin of an ulnar nerve from a median nerve-a case report. Journal of Clinical and Diagnostic Research. 2011;5(6):1270-1271.

7. Aktan ZA, Öztürk L, Bilge O, et al. A cadaveric study of the anatomic variations of the brachial plexus nerves in the axillary region and arm. Turk J Med Sci. 2001;31(2):147-150. 